\title{
EL DESTINO DE MIDAS
}

\section{Giovanni Berlinguer}

Università di Roma La Sapienza

Esta breve nota podría tener el siguiente subtítulo: «Cómo el ignorar la existencia de un artículo de Gramsci me ha permitido escribir un libro, y cómo el descubrimiento de dicho artículo me ha ayudado después a comprender mejor su significado».

Pero procedamos con orden, desde el primer capítulo de la historia. Al inicio de los años noventa, instigado por las frecuentes y horribles noticias de niños comprados y vendidos en Brasil con el objeto de extraer sus órganos para usarlos con la intención de realizar trasplantes, comenzé a recoger datos y noticias tanto sobre estos episodios, como sobre el hecho de que las tecnologías biomédicas, junto a indudables ventajas para la vida humana, pueden abrir el camino a la transformación de nuestro cuerpo en objeto de mercado: ya nunca más comprado y vendido como «cuerpo total», como ocurrió con la esclavitud, sino como «partes separadas»: órganos y sangre, tejidos y gametos, úteros y DNA. Ya que esta tendencia se manifiesta en un periodo en el que gran parte de la vida humana, incluidos los pensamientos y los sentimientos, corre el riesgo de caer bajo el dominio del mercado, al final de esta tendencia invasiva podría ocurrir que nosotros mismos nos convirtieramos en el signo extremo de este dominio: exactamente en la mercancía final.

Algún año después (capítulo segundo) vino a Roma con una beca, a trabajar conmigo durante un año, un joven colega brasileño, Volnei Garrafa, cuyos abuelos italianos se llamaban Caraffa y cuyo apellido se había transformado durante la emigración. Su programa de investigación trataba sobre la reforma de los servicios sanitarios en Italia, aprobada en 1978, y considerada ejemplar, justa o injustamente, en Brasil. La investigación, sin embargo, presentaba desde su inicio dos inconvenientes. Uno, el hecho de que la reforma de 1978 casi se había volatilizado durante este tiempo, a causa de los cambios en el clima político de los años ochenta, de los golpes de maza de De Lorenzo (Ministro Liberal de la Salud) y socios y, quizá también, a causa de algunos de sus defectos. El otro inconveniente -para Volnei más grave- es que, mientras tanto, yo me había desenamorado de este campo de estudio y me había dedicado a la bioética, quizá buscando en el campo moral una revancha frente a las dificultades políticas. Le dije: « Puedo ayudarte, si quieres. Pero mientras, mira estos documentos y estas notas, que hablan también de tu país, y dime si te interesan ». Volnei desapareció durante quince días, y cuando ya estaba preocupado por la suerte de mis papeles regresó y me preguntó: «¿Cuándo empezamos a trabajar en esto?».

El capítulo tercero ha durado dos años, vividos al principio juntos y, después, mediante comunicaciones de correo electrónico y envío de disquetes con los diversos capítulos del libro de Roma a Brasil y viceversa. Volnei verificó todos los rumores sobre «robos de órganos», y resultó que ningún caso estaba suficientemente documentado. Una leyenda plausible, por lo tanto, no una realidad. 


\section{ENSAYOS}

Descubrimos, sin embargo, algo peor (si es posible): una extensión del mercado legal de los órganos extraídos de un vivo, por ejemplo en la India; una ampliación del «catálogo» de las mercancías humanas a medida que un nuevo pedazo se mostraba extraíble de un individuo y transferible a otro; y, finalmente, un fenómeno quizá aun más grave que los hechos en sí mismos: el manifestarse, junto a un generalizado rechazo entre la opinión pública, una tendencia a justificar la compraventa por parte de cualificados cirujanos y de acreditados filósofos.

Para concluir, nuestro libro, que comprendía una descripción de los hechos, una discusión de las causas y de las consecuencias, un análisis de los argumentos a favor y en contra, y algunas líneas alternativas al mercado, fue terminado y publicado contemporáneamente, en 1996, en Brasil y en Italia ${ }^{1}$. Para evitar (como temo ya haya ocurrido), que esta nota sea considerada un pretexto publicitario, llego al último capítulo de la historia: la sensación de ridículo y la feliz revelación, al escuchar a un joven amigo decirme: «¿Pero no sabes que Gramsci se ocupó del mismo argumento, hace unos ochenta años?».

La ignorancia, lo confieso, ha salvado el libro. Si hubiera leído su artículo, escrito el 6 de junio de 1918, probablemente habría renunciado a él: porque ya está todo, y algo más.

\section{La mercancía}

Algún frívolo ha proclamado por enésima vez la derrota de la ciencia.

Química aplicada a gases asfixiantes, lacrimógenos, ulcerantes; mecánica aplicada a cañones de largo alcance.... Sí, pero también la azada puede romper cráneos, la escritura también puede servir para falsificar pagarés y para redactar cartas anónimas... Y no por eso, se proclama la derrota de la agricultura y de la caligrafía.

La ciencia tiene el deber desinteresado de descubrir relaciones nuevas entre las energías, entre las cosas. Fracasa sólo cuando se convierte en charlatanería. ¿Los hombres se sirven de los descubrimientos para atormentar y matar en lugar de para defenderse del mal y de las ciegas fuerzas naturales? Entra en juego una voluntad que es extraña a la ciencia, que no es desinteresada, sino que depende intrínsecamente de la sociedad, de la forma de sociedad en la que se vive. El descubrimiento científico sigue la suerte de todos los productos humanos en el régimen capitalista; se convierte en mercancía, en objeto de cambio y, por lo tanto, se dirige prevalentemente a los fines propios del régimen, a atormentar y a destruir.

He aquí que el doctor Carrel ha abierto una nueva vía a la cirugía: las posibilidades de injertos humanos ahora se multiplican.

Aún no hemos llegado a la intensidad prevista por Edmondo Perrier: el injerto de cerebro, el uso de los órganos de los cadáveres para sustituirlos en los vivos por los órganos sanos deteriorados. Aún estamos lejos de la victoria científica sobre la muerte prometida por Bergssu [probable error de impresión por Bergson]: por ahora la muerte es triunfadora y para triunfar más rápidamente hace uso con prodigalidad de la ciencia y sus secretos. Pero llegaremos. La vida también se convertirá en mercancía si el régimen capitalista no se sustituye, si la mercancía se abole.

1 GiovanNi Berlinguer y VOlNei GaRRAFA, La merce finale -Saggio Sulla compravendita di parti del corpo umano-, Milano, Baldini e Castoldi, 1996. O mercado humano, Brasilia, Editora UnB (Universidad de Brasilia),1996. A mercadoria final, Alges (Portugal), Difel, 1997. 
Según una conferencia celebrada en la Academia de medicina de París, el profesor Laurent ha logrado sustituir el corazón de Fox por el de Bob, y viceversa, sin que los dos inocentes perros hayan sufrido demasiado, sin turbar para nada la vida de la delicada víscera. Desde este momento el corazón se ha convertido en una mercancía: puede ser cambiado, puede ser comprado. ¿Quién quiere cambiar su corazón desgastado, por un corazón nuevo y flamante, pobre, pero sano, pobre, pero que siempre ha palpitado honestamente? Una buena oferta: está la familia que mantener, el futuro de los hijos preocupa a los padres; uno cambia por tanto el corazón para que no parezca que carece de él.

El doctor Voronof ya ha anunciado la posibilidad del injerto de ovarios. Un nuevo camino comercial abierto a la actividad exploradora de la iniciativa individual. Las pobres jóvenes podrán hacerse fácilmente una dote. ¿Para qué sirve su órgano de la maternidad? Lo cederán a la rica señora infecunda que desea una prole que herede sus sudados ahorros matrimoniales. Las pobres jóvenes ganarán dinero y se librarán de un peligro. Ya venden sus rubias cabelleras para las cabezas calvas de las «cocottes» que se casan y quieren entrar en la buena sociedad. Venderán la posibilidad de convertirse en madres: darán fecundidad a las viejas ajadas, a las corrompidas señoras que se han divertido demasiado y quieren recuperar el tiempo perdido. ¿Los hijos nacidos tras un injerto? Extraños monstruos biológicos, criaturas de una nueva raza, también ellos mercancías, producto genuino de la empresa de los sucedáneos humanos, necesarios para trasmitir la estirpe de los charcuteros enriquecidos. La vieja nobleza tenía indudablemente mayor buen gusto que la clase dirigente que la ha sucedido en el poder. El dinero estropea, embrutece todo aquello que cae bajo su ley implacablemente feroz.

La vida, toda la vida, no solo la actividad mecánica de las artes, sino la misma fuente fisiológica de la actividad, se separa del alma, y se convierte en mercancía de cambio; es el destino de Midas, el de las manos hechizadas, símbolo del capitalismo moderno.

Antonio Gramsci (Avanti !, 6 de junio de 1918)

Añado solo algún breve comentario. En primer lugar, sobre la época. Junio de 1918, hacia el final de la «inútil masacre» (¡Cuantas más la seguirían, justo hasta nuestros días!): una fase en que la muerte, como sucederá después, en agosto de 1945, en Hiroshima y Nagasaki, utiliza con prodigalidad la ciencia y sus secretos. En los mismos años progresaban, sin embargo, las ciencias biomédicas. Alexis Carrel, medico humanista y premio Nobel de medicina, abría el camino a los injertos humanos (después se llamaron trasplantes) logrando unir los vasos sanguíneos (anastomosis), Richard Lewisohn conseguía volver incoagulable y por tanto trasportable la sangre humana, y al mismo tiempo diversos cirujanos experimentaban intercambios de órganos entre animales, con la perspectiva -por primera vez en la historia- de poder transferir materia vital de un individuo a otro.

Gramsci defiende la ciencia, cuyo deber es el de «descubrir nuevas relaciones entre las energías, entre las cosas», y dirige su acusación hacia la sociedad que transforma el descubrimiento científico en mercancía y en instrumento de exterminio. El realiza, por tanto, una distinción entre el conocimiento científico y sus aplicaciones, que hoy puede ser menos neta pero que permanece sustancial. Cuando se olvida esta distinción, es fácil proporcionar una coartada a las distorsiones perpetradas y a los abusos realizados por los que dominan las tecnologías, y es aun más fácil caer en nostalgias precientíficas y en ideologías espiritualistas 
ENSAYOS

En cuanto a la previsión de que no sólo la actividad mecánica de las artes (el trabajo asalariado), sino cualquier parte del cuerpo, la misma fuente de la vida, pudiese convertirse en mercancía de cambio, es verdaderamente asombrosa. El cuadro de las pobres jóvenes y de las «corrompidas» señoras, de los charcuteros enriquecidos que quieren trasmitir a cualquier precio su estirpe, del intercambio de corazones, describe con un muy eficaz lenguaje de la época fenómenos que pertenecen a nuestra realidad. Aun no generalizados ni legalizados, afortunadamente, porque si bien es cierto que Midas puede simbolizar el destino del capitalismo moderno, espero que haya también fuerzas morales y políticas que puedan impedir que esto suceda. 